\title{
A Estação: um testemunho da cultura visual da belle époque na difusão das técnicas de construção de roupas
}

A Estação: a testimony of belle époque's visual culture in the dissemination of dressmaking techniques

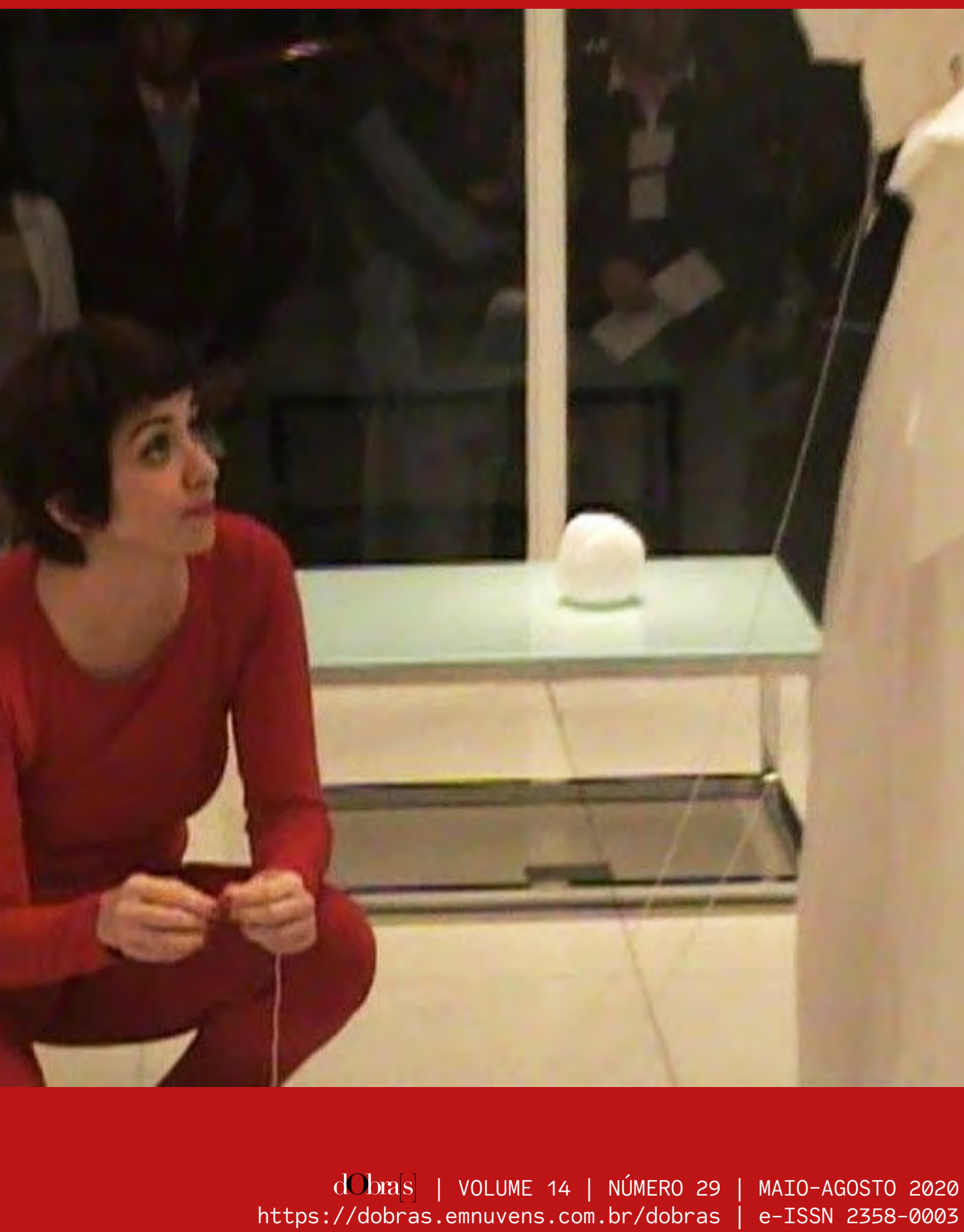




\section{Maristela Novaes ${ }^{1}$}

ORCID: https://orcid.org/0000-0001-7704-2098

[resumo] Neste artigo, investigo o uso da cultura visual como veículo de informação de moda e de técnicas de construção de roupas divulgadas no periódico A Estação (18791904). 0 estudo se baseia na análise de exemplares desse periódico, em português e em sua versão francesa (La Saison, 1883-1908), e de um exemplar do manual de corte e costura que o complementava. Objetivo compreender o uso dos recursos visuais na comunicação de moda e na formação de uma cultura francesa de construção de roupas que, pelos portos litorâneos, entrava no país chegando aos confins de Minas Gerais. Para isso, investigo os conteúdos textuais e imagéticos dos impressos, a legislação educacional da Primeira República, fotografias e um objeto têxtil. Como procedimento teórico-metodológico parto do entrecruzamento dos impressos com várias outras fontes numa perspectiva dialética que situa o contexto histórico e os recursos da cultura visual, permitindo compreender sua abrangência na absorção da moda e no ensino-aprendizagem das técnicas francesas de construção de roupas na belle époque brasileira.

\section{[palavras-chave] Comunicação. Modernidade. Técnicas de construção de roupas. Belle époque. Brasil.}

[abstract] This article investigates the use of visual culture as a vehicle for fashion information and dressmaking techniques published in the periodical A Estação (18791904). The study is based on the analysis of Portuguese and French issues of the journal (La Saison, 1883-1908), as well as a cut-and-sew manual that accompanied it. The aim is to understand the use of visual resources in fashion communication and the formation of French dressmaking culture - which entered the country via seaports before reaching the utter ends of Minas Gerais. In order to reach this objective, the textual and imagistic contents of the cited journal, the educational legislation of the First Republic, photographs, and a textile object were investigated. As a theoretical-methodological procedure, the material was intertwined with many other sources from a dialectical perspective. This choice makes it possible to situate the historical context and the visual culture resources, allowing us to understand its comprehensiveness when it comes to the absorption of fashion and the teaching of French dressmaking techniques in the Brazilian belle époque.

[keywords] Communication. Modern times. Dressmaking techniques. Belle époque. Brazil.

Recebido em: 30-01-2019

Aprovado em: 19-07-2019

\footnotetext{
1 Doutora em Studi Storici pela Università di Bologna-UniBO. Professora adjunta I no curso de Design de Moda da Universidade Federal de Goiás. E-mail: telanovaes@gmail.com. Lattes: http:// lattes.cnpq.br/3596213313236544.
} 


\section{Introdução}

O jornal que surge em 1879 como A Estação: Jornal Ilustrado para a Família, e que, na edição de 15 de abril de 1896, passa a ser apresentado como A Estação: Jornal de Modas Parisienses dedicado as ${ }^{2}$ Senhoras Brasileiras ${ }^{3}$ foi considerado, na passagem do século XIX para o XX, um embaixador da cultura francesa no Brasil (BASTOS, 2000). Esse jornal circulou no país até 1878 em língua francesa, acompanhado de anexo em português. De 1879 a 1904 foi traduzido para o português, com periodicidade quinzenal. Ele era publicado pela casa tipográfica Lombaerts no Rio de Janeiro (DUARTE, 2017) e distribuído em todo o país, alcançando regiões centrais do Brasil, como Uberaba, em Minas Gerais, considerada, então, a "Boca do Sertão", como comprova a correspondência n. 66.127 do jornal (A ESTAÇÃO, 15 novembro de 1900). Em Villa Platina, hoje Ituiutaba, Triângulo Mineiro, não encontramos testemunhos de circulação da publicação, mas fontes imagéticas (OLIVEIRA, 2016; CNSD, 1908-1940) e têxteis (NOVAES, 2010; NOVAES, 2018) que materializam os conteúdos de moda divulgados pelo jornal.

Nos 32 anos de circulação no Brasil, $A$ Estação usou a cultura visual, entendida como os recursos imagéticos (HERNÁNDEZ, 2006), para a circulação de ideias e de cultura material relativa a comportamentos, a gostos, a modas, a figurinos, à cultura e às técnicas de construção de roupas (corte, costura e bordados) no Ocidente, chegando a conectar culturas falantes de 14 línguas. Os editoriais e figurinos sugeriam tecidos e aviamentos que vinham de países industrializados, como Inglaterra e França, e chegavam aos centros comerciais do Brasil de onde eram enviados para todo o país. Essa distribuição passava por Uberaba, ou Uberabinha, alcançando Villa Platina (MARTINS FILHO, 1915), à época município confinante com Goiás. Além de divulgar figurinos e matérias-primas, o jornal vendia moldes, manuais técnicos e um estojo de instrumentos necessários às técnicas de construção de roupas da belle époque. Esse momento coincide com aquele em que a educação feminina passa a ser um projeto do Estado, cujo objetivo principal era a habilitação das prendas domésticas voltadas à economia do lar (conteúdos desenvolvidos nas disciplinas de costura e de trabalhos de agulha). Sendo o Brasil um dos primeiros países a adotar o sistema métrico decimal cuja invenção é francesa (MILANEZ, 1942), o jornal A Estação será também um grande difusor desse sistema de mensuração no país.

O objeto deste artigo é refletir sobre o uso da cultura visual adotada pelo jornal como um veículo de formação (ensino-aprendizagem ${ }^{4}$ ) nas técnicas de costura e de difusão do sistema métrico pelo Brasil. Isso se deu em um entrelaçamento que envolveu o Estado brasileiro, a educação confessional, a educação laica, a educação profissional e os impressos da

\footnotetext{
Conservei as grafias originais dos documentos pesquisados.

3 jornal A Estação encontra-se disponível na Casa Rui Barbosa e na BNDigital, ambas do Rio de Janeiro. La Saison encontra-se disponível na Trencadis de Barcelona.

4 Adoto o termo "ensino-aprendizagem" por acreditar que a formação é sempre um caminho de mão dupla (NOVAES, 2011, p. 34), mesmo na relação revista-leitor(a) isso é perceptível.
} 
editora Lombaerts, que compreendem o jornal de moda $A$ Estação, os manuais técnicos de modelagem, os de costura e os de bordados, no ensino-aprendizagem da cultura de técnicas de construção de roupas nesse período.

Com a análise desses documentos, busco uma compreensão mais sistemática e fundamentada do processo de formação da cultura de construção de roupas por meio da cultura visual do jornal. Para tanto, examino a legislação educacional e a formação em corte e costura, os recursos visuais na comunicação de moda e de técnicas de manufaturas de roupas e o entrelaçamento do estado e das publicações de moda no ensino de "corte e costura" na belle époque brasileira.

\section{Métodos e fundamentação teórica para uma análise de $\boldsymbol{A}$ Estação}

Este estudo é embasado na pesquisa documental e bibliográfica e se estrutura como descrição e interpretação pelos métodos dialético e historiográfico por meio de operações, como contextualização, associação, comparação, análise e ampliação. Segundo Daniel Roche,

[a] história social urbana percebeu, sobretudo graças à utilização dos inventários póstumos, a importância da roupa, não tanto nos patrimônios quanto nos modos de vida e nas relações humanas. A lógica da roupa oferece uma maneira de compreender e um meio de estudar as transformações sociais que ocorrem nos aglomerados urbanos. (ROCHE, 2007, p. 20)

Fernand Braudel (2006), nos seus estudos sobre as roupas e a moda, já havia advertido a respeito da associação da cultura material com os comportamentos. Segundo o historiador,

[a] história das roupas é menos anedótica do que parece. Ela coloca todos os problemas: das matérias-primas, dos processos de transformação, dos custos, das imobilidades culturais, das modas, das hierarquias sociais. Mudando ao sabor das vontades, a roupa revela em qualquer lugar, e com obstinação, os contrastes sociais $^{5}$. (BRAUDEL, 2006, p. 282)

A moda, ou as modas, incita a mudanças àqueles que se preocupam com as aparências, pois que servem a exibir poder e distinção, e abarca vários aspectos da vida humana. No que se refere às aparências,

[a] moda situa-se no cruzamento do fato de vestir, que um indivíduo pode lançar e generalizar no sistema indumentário, em que ela se torna propriedade comum, com o fato de vestimenta, generalizada numa maneira de vestir e reproduzida em escala coletiva, na alta-costura, por exemplo. (ROCHE, 2007, p. 59)

\footnotetext{
Tradução minha para "texto italiano".
} 
Essa reprodução, no entanto, se daria dentro e fora dos circuitos das elites aristocráticas e muito antes da consolidação da haute couture (MENDES, 2014). Entre os séculos XVII e XVIII, esse grande fenômeno denominado moda

recebeu um novo ímpeto, propiciando sua difusão além da França, que agora dá o tom para toda a Europa. Um dos fatores mais importantes, embora bastante negligenciado, nesse desenvolvimento era de ordem econômica: a existência de uma indústria de roupa de luxo, concentrada em Paris, com uma tradição, clientes e grandes interesses em jogo. Para sobreviver ela precisava manter um fluxo de novas roupas e, para expandir, necessitava acelerar a frequência com que eram substituídas. (ROCHE, 2007, p. 57)

É nesse contexto que floresce a imprensa de moda, e Paris, o grande laboratório de criação de vários estilos diferentes de vida e de modos de vestir para ricos e para pobres, torna-se a meca da moda ocidental. Sobre o processo de aceleramento do fluxo de substituição de roupas, Daniel Roche (2007) afirma:

[...] os anos após 1750 viu o desenvolvimento de uma imprensa de moda que, embora essencialmente francesa, era lida muito além das fronteiras da França. Ela ajudou a remodelar a roupa das elites europeias - o público leitor - à imagem das sensibilidades mundanas francesas, do mesmo modo que a conduta e a cultura dessas mesmas elites haviam sido anteriormente influenciadas pelos luminares da filosofia francesa, cujas idéias ${ }^{6}$ tinham circulado pelos canais cada vez mais numerosos dos livros e da imprensa. (ROCHE, 2007, p. 473)

No Brasil, aproximadamente um século depois do florescimento da imprensa de moda, os períodos de decadência da monarquia e de

[...] instauração de uma ordem republicana foram preparados por uma longa maturação ideológica onde as principais referências são a França das Luzes, a Revolução Francesa e as correntes de pensamento em voga na Europa, especialmente o positivismo. (CARRELLI, 19937 , citado por BASTOS, 2000, p. 81)

Os luminares da filosofia francesa chegavam ao país por meio da imprensa que, a partir da transferência da família real portuguesa de Portugal para o Rio de Janeiro, se instalava na capital. Tipógrafos e livreiros alemães e franceses foram fundamentais na consolidação da imprensa no país (SODRÉ, 1977). Dos valores veiculados em livros e jornais, três

\footnotetext{
${ }^{6}$ Para as citações, nomes de documentos e de pessoas, adoto a grafia que consta no documento original.

7 CARELLI, Mario. Cultures croisées. Histoire des échanges culturels entre Ia France et le Brésil de Ia découverte aux temps modernes. Paris: Nathan, 1993.
} 
instituições podem ser marcadas pela influência e o prestígio da França no Brasil do século XIX: a Guarda Nacional, a Escola de Minas e o Jornal das Familias (FRÉDÉRIC 1991², citado por BASTOS, 2000).

No século XIX, O Jornal das Familias, do editor Garnier, e A Estação, do Lombaerts, agitavam o gosto com modelos e figurinos vindos da França (SODRÉ, 1977; COSTA, 2012). Esses jornais, somados às inúmeras revistas estrangeiras, seriam grandes agentes a incitar as mudanças nos gostos (COSTA, 2012), nas aparências e nas técnicas de construção de roupas no Brasil. Títulos em língua francesa, inglesa e italiana eram vendidos pelo próprio editor de A Estação, que se gabava de ser o maior representante desse gênero de jornais no país (15 de janeiro de 1904, capa). Em Uberaba, interior de Minas, eram também comercializados pela Livraria Universal da viúva Leschaud \& Filha (ALMANACH UBERABENSE, 1903, s.p.).

Esses "novos meios de comunicação permitiram que um novo universo de símbolos se propagasse e uma nova ideologia se difundisse ao serem projetados na materialidade das coisas" (ROCHE, 2007, p. 474). 0 objetivo dos jornais de moda era apresentar coleções de roupas conjugando texto e imagem. Para a exploração dos aspectos estéticos, do potencial comunicativo dos recursos imagéticos do jornal A Estação e dos manuais que o complementavam, objetos deste artigo, o referencial teórico-metodológico se amplia em um diálogo transdisciplinar com os campos da Arte e da Cultura Visual (HERNÁNDEZ, 2006).

No entrecruzamento de métodos e referenciais teóricos, busco articular a dimensão nacional (Brasil), regional (Minas Gerais) e local (Villa Platina/Ituiutaba) da formação institucional e informal em construção de roupas, permeados pelas informações divulgadas nos impressos da editora. As fontes de pesquisa incluem fotografias, ilustrações de moda, a legislação educacional da primeira República, o jornal de moda, os manuais técnicos, diversos jornais regionais e nacionais, livros contábeis e, por fim, um objeto têxtil.

Analiso a legislação educacional republicana, implantada com a Reforma Benjamin Constant (BRASIL, 1890) e com a Reforma João Pinheiro (MINAS GERAIS, 1906; MINAS GERAIS, 1907), que foi adotada pelos nascentes grupos escolares no Estado de Minas Gerais e com a qual vislumbro a formação em "corte e costura" no interior do Brasil. Anterior à implantação da escola laica, fez-se presente a educação confessional das freiras dominicanas no Colégio Nossa Senhora das Dores em Uberaba (CNSD), porta de entrada do Triângulo Mineiro, e que atendia a educação da oligarquia rural e uma parcela de "meninas ingênuas" (MONITOR UBERABENSE, 17 de outubro de 1885). Dada a importância dessa escola feminina na divulgação da cultura francesa no sertão de Minas, analiso o programa de ensino do CNSD (MONITOR UBERABENSE, 17 de outubro de 1885).

A educação confessional e laica previa disciplinas e atividades de "trabalhos de agulha" e de "economia doméstica", ambos para o sexo feminino. Como material didático de apoio a essas disciplinas, eram indicados os manuais vinculados ao jornal de moda de maior

\footnotetext{
8 MAURO, Frédéric. O Brasil no tempo de D. Pedro II (1831-1889). São Paulo: Companhia das Letras, 1991.

9 "Órfãs e ingênuas" era a denominação corrente para crianças nascidas livres de mães escravas após a Lei do Ventre Livre.
} 
difusão no território brasileiro, $A$ Estação. Esse jornal reforçava o discurso de educação feminina presente na legislação educacional republicana ao mesmo tempo que informava e qualificava tecnicamente costureiras e afins.

\section{A legislação educacional e a formação em corte e costura}

Segundo Paulo Krüger Corrêa Mourão (1962, p. 14), “a França influía não só nas ideologias e na moda, mas também sobre a metodologia de ensino utilizada em Minas, pelo menos em grande parte do período imperial". Essa influência, que se caracteriza muito pela orientação positivista, sobreviverá à instauração da República, em 1889.

A instrução educacional do novo regime de governo no Brasil foi inaugurada com a Reforma Benjamin Constant (BRASIL, 1890). No entanto, a inserção do programa educativo republicano em Villa Platina, confins de Minas com Goiás, se deu em 1910 com a inauguração do Grupo Escolar Villa Platina, que implantaria ali o programa definido pela Reforma João Pinheiro (MINAS GERAIS, 1906; MINAS GERAIS, 1907), ocorrida em 1906. Entre as duas reformas, uma sequência de leis e mudanças incrementou a instrução formal republicana no país. Na análise dos programas escolares do CNSD e dessas duas reformas, que detalham matérias e conteúdos, podemos ver com clareza como a escola formal religiosa ou laica tratava a formação feminina desde as vésperas da mudança de regime governamental até a primeira década do século XX.

O CNSD, de origem francesa, foi a primeira escola dominicana para meninas no Brasil e a primeira destinada à educação feminina no Sertão da Farinha Podre. Foi inaugurada em 1885 como a escola elementar e, em 1906, inaugurou a Escola Normal (BICHUETTE, 1986). Essa instituição teve um grande impacto na região do Triângulo Mineiro, em Goiás e em parte do interior de São Paulo (CNSD, 1908-1940).

Em 1885, na seção "Publicações Pedidas" do Jornal Monitor Uberabense 17 de outubro de 1885), o CNSD publicou um anúncio que nos possibilita alcançar o panorama de todo o funcionamento do colégio: perfil de alunas, matérias, sistema de matrícula etc. O programa da escola primária apresenta "trabalhos manuais próprios de uma senhora como: costura, tricô, bordados, etc." Podemos pensar que, sendo a escola dirigida por freiras de Monteils, França, a afirmação de Paulo Krüger Corrêa Mourão (1962) tenha sentido e que a influência das ideologias francesas no ensino dos "trabalhos manuais" em Uberaba tenha sido direta.

Cinco anos após a inauguração do CNSD, e como uma primeira ação para afrontar o problema da educação no Brasil republicano, o Decreto 981 (Brasil, 1890) regulou o ensino primário e o secundário, bem como criou o Conselho de Instrução Superior na República e o Pedagogium (BASTOS, 2000). A lei organizou o ensino primário em primeiro e segundo graus. Disciplinas como "Língua Pátria” ou "Língua Portugueza”, “Calligraphia”, "Leitura”, "Geometria”, “Desenho", "Arithmetica”, “Noções de Álgebra” e "Desenho”, presentes nas reformas que vão da de Benjamin Constant à de João Pinheiro, ou seja, ao longo de 16 anos, seriam aquelas que dariam uma contribuição direta à formação de um construtor de roupas (costureira ou alfaiate), pois, no conjunto, leitura, coordenação motora e visão espacial favoreciam a assimilação da moda e das técnicas de construção de roupas impressas nos jornais. 
A velocidade do fluxo de novas propostas de figurinos com grande variação de formas, de tecidos e de aviamentos, que implicavam em diversas e distintas técnicas de manufatura, até então era inédita no Ocidente. Essas técnicas, assim como o projeto de educação republicano, eram orientadas pelo positivismo. As matérias que se ocupavam do "Systema Metrico Decimal" associado ao ensino de "Geometria" e de "Arithmetica" seriam fundamentais para a capacitação em modelagem, e o "francez" seria a língua que permitiria ao construtor de roupas ler os inúmeros jornais que divulgavam a moda diretamente da fonte, Paris, a meca da moda ocidental.

No que toca as disciplinas específicas daquilo que podemos pensar uma educação profissional, a Reforma Benjamin Constant propôs, com os "trabalhos de agulha", uma formação feminina que ia dos 7 aos 15 anos. A Reforma João Pinheiro, ao contrário, apresentou conteúdos mais aprofundados em "trabalhos de agulha" e em "costura" em uma formação de três anos e meio. Esse estudo iniciava-se com "dobraduras em tecido e em papel", passando para o "corte e fabrico de roupas simples" até chegar ao "uso da máquina de costura movida a pedal e a mão" na confecção de roupas complexas (MINAS GERAIS, 1906). A formação em costura mecânica fazia sentido, pois a máquina de costura Singer já era divulgada, em vendas no atacado, pelo Almanak Laemmert (1859) desde 1859 no Rio de Janeiro, um dos polos comerciais do país.

A ideologia, a metodologia e as matérias das reformas educacionais seguiram as orientações da educação europeia, inclusive em relação à formação em costura, em trabalhos femininos e em economia doméstica como conteúdo da instrução institucional republicana. Entre o programa apresentado pelo CNSD e as duas reformas, constatamos que o "Systema Métrico Decimal" passa de matéria a conteúdo de "Arithmetica", o que demonstra a absorção no sistema de mensuração no país ao longo desse período.

Na Reforma de João Pinheiro (MINAS GERAIS, 1906), rechaçava-se o método "sillabico" na alfabetização, por ser "universalmente condenado pelo ensino moderno" e recomendava-se o método "intuitivo" inspirado em Pestalozzi.

O ensino intuitivo fundamentava-se na premissa de que, a partir dos objetos do cotidiano, "as coisas" do mundo real, a intuição infantil seria capaz de construir e expressar ideias. Implícita nestas novas concepções educacionais estava a rejeição à memorização como método de ensino. (D’ESQUIVEL, 2015, p. 372)

Na matéria de “Geometria e Desenho", a lei determinava:

I. Todas as noções devem basear-se em cousas concretas, utilizando-se os objetos da classe, do predio e do pateo para o estudo das linhas, dos angulos, das extensões lineares, quadradas e cúbicas, etc.

II. 0 desenho tenderá a reprodução de objectos, a principio por linhas rectas, depois por curvas, augmentando-se gradualmente as dificuldades. (MINAS GERAIS, 1906, s.p.) 
Para a formação nessa matéria, especificamente destinada ao sexo feminino, a lei prescrevia:

\begin{abstract}
I. Familiarizem-se as meninas, desde o primeiro dia, com os utensílios do trabalho doméstico, ensinando-lhes, somente o que for útil e pratico. Os trabalhos de fantasia devem ser banidos, ficando a cargo da familia.

II. Faça-se que a menina, ao deixar a escola, possa se servir das próprias mãos, na execução das peças do vestuário e mais trabalhos communs da vida domestica, para ser desde logo útil a si e á família. (MINAS GERAIS, 1906, s.p.)
\end{abstract}

Essa formação, por um lado, implicava que as meninas fossem submetidas, desde muito cedo, a rigorosos "adestramentos" das mãos, em família ou na escola. Esse "adestramento" objetivava educar a coordenação motora e a precisão no desenvolvimento dos pontos de costura e de bordado (MALERONKA, 2007), que deveriam ser regulados pela direção, pela forma e pelo equilíbrio das tensões dos fios. Por outro lado, a lei determinava que a "fantasia" deveria ser banida da disciplina de "Geometria e Desenho", o que poderia dificultar às alunas relacionarem esses conteúdos à moda e aplicá-los na modelagem de roupas. 0 programa previa o desenvolvimento da coordenação motora tanto para os trabalhos manuais como para os mecânicos, tornando possível a manufatura de peças de roupas com técnica híbrida.

Retomando o método "intuitivo", Rui Barbosa, um dos idealizadores do projeto educacional republicano, "ciente da necessidade de um manual pedagógico através do qual professores brasileiros pudessem conhecer a teoria e a prática das técnicas de Pestalozzi" (BASTOS, 2000, p. 86), introduziu o livro de Norman Allison Calkins, Lessons for training (1870), no projeto de instrução pública do Brasil.

A obra foi traduzida por Rui Barbosa em 1881 e adotada pelas escolas como manual endereçado aos professores, para orientar e estruturar as aulas e as atividades didáticas. 0 método "intuitivo" foi adotado pela Reforma Benjamin Constant para toda a federação, e o livro "tornou-se o manual para professores mais difundido e usado no Brasil, durante os anos finais do Império e grande parte da primeira República (1889-1930)” (BASTOS, 2000, p. 85).

Nos programas de ensino desse período, embasados em Lessons for training e no método "intuitivo", não encontramos a preocupação com o desenvolvimento da criatividade na formação institucional. A exclusão dos trabalhos de "fantasia" no âmbito da escola e a orientação à "reprodução" dos objetos na matéria de "Geometria e Desenho" da Reforma João Pinheiro exprimiam tendências que certamente dificultavam o desenvolvimento da criatividade e da leitura de figurinos e moldes por parte das alunas. A geometria era a base da concepção de modelagem difundida pela indústria dos moldes de papel (EMERY, 2014) na belle époque e os exercícios das figuras geométricas eram alicerce para o conhecimento da relação entre corpo e forma (SELTIMI, 1942). Uma vez aprendido na escola, esse procedimento poderia ser transferido, por analogia, para o vestuário, como podemos ver na figura 1, pois uma roupa é um objeto tridimensional que pode ser construído a partir do bidimensional, como o faz a técnica de modelagem geométrica. 
No desenvolvimento das técnicas de modelagem e de costura, ao longo dos séculos XVIII e XIX, aquela, cuja gênese é a geometria, foi a que primeiro se adequou aos métodos de produção industrial (SELTIMI, 1942). Ela era orientada pelo cientificismo e pelo positivismo e exigia como pré-requisitos operações básicas de matemática e o domínio de uso de utensílios específicos para a confecção de moldes personalizados. Inúmeros métodos de corte e costura, resultados da técnica de modelagem geométrica, foram criados na França, na Inglaterra e, em menor parte, na Itália (SELTIMI, 1942). Posteriormente, esses métodos foram difundidos no território brasileiro e essa técnica de modelagem tornou-se hegemônica no Brasil. Seguir as alterações da moda e das orientações de costura nos jornais implicava como base a alfabetização e, para além disso, os conhecimentos específicos já mencionados: de matemática, de geometria, de desenho e de francês.

FIGURA 1 - FIGURINO EM VISTA FRONTAL, EM MOLDES E EM VISTA POSTERIOR

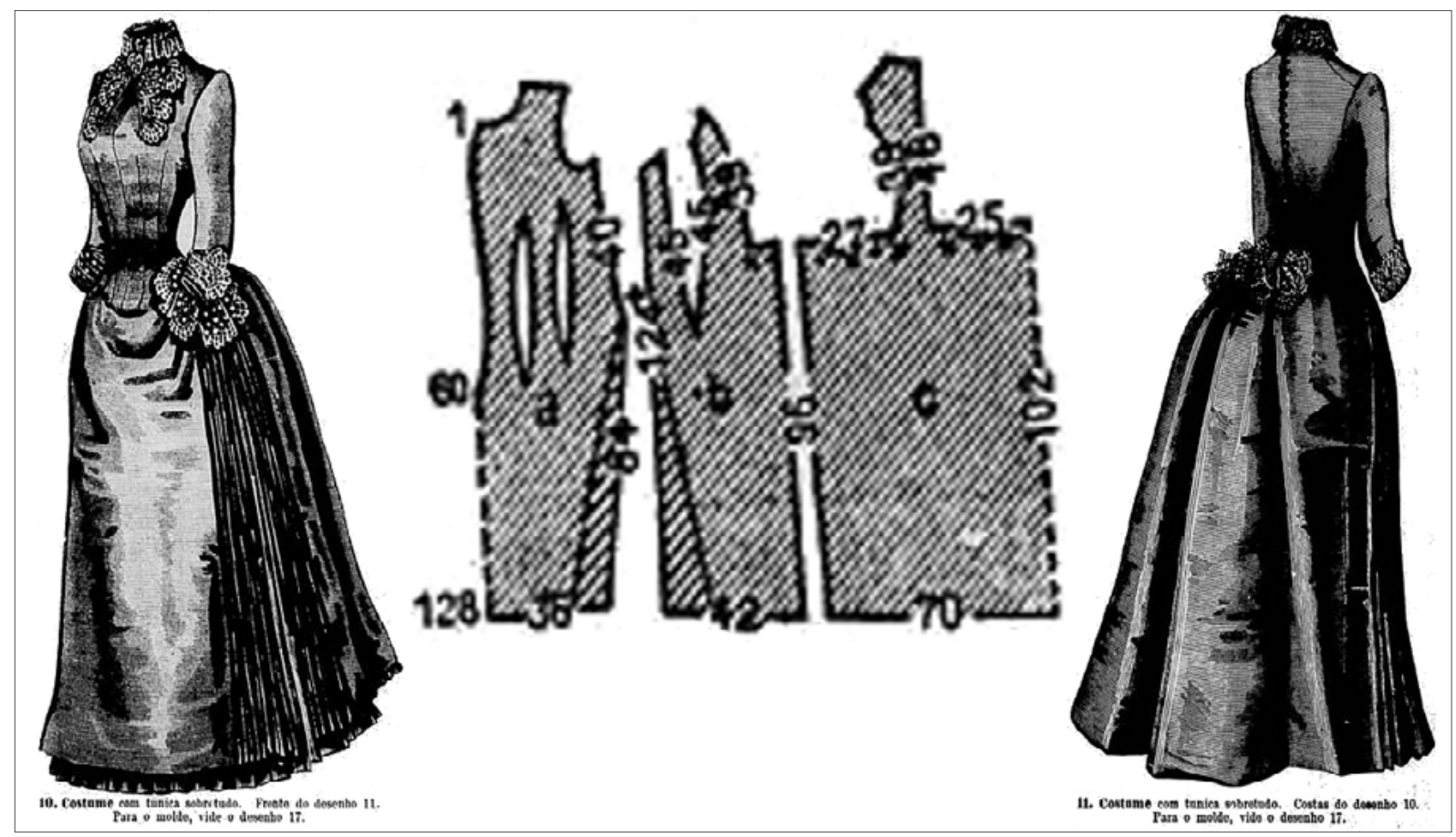

FONTE: A Estação, 30 de junho de 1886, p. 90. BNDigital - Biblioteca Nacional Digital do Brasil.

Na perspectiva de uma formação que restringia o desenvolvimento das habilidades na disciplina de "Geometria e Desenho", podemos pensar que essa formação possibilitava antes a reprodução dos moldes dos jornais do que a sua confecção.

Os recursos visuais na comunicação de moda e de técnicas de corte e costura

A Estação se enquadra no tipo de publicação descrito por Silvia Franchini como aquele especializado no "tema moda e na sua imagem como forma de publicação de modelos de roupas e de acessórios reproduzíveis em larga escala” (FRANCHINI, 2002, p. 22). Trata-se 
de um jornal de caráter técnico-profissional endereçado "a toda mai (de família que deseje trajar e vestir suas filhas” (A ESTAÇÃO, 15 de janeiro de 1879, capa), como pregava o programa de ensino do CNSD (MONITOR UBERABENSE, 17 de outubro de 1885) e a legislação educacional republicana (BRASIL, 1890; MINAS GERAIS, 1906).

A atividade de costura foi uma das possibilidades de inserção da mulher no mercado de trabalho, uma vez que permitia à costureira o exercício da profissão no seio da vida doméstica. Entre o público e o privado, as costureiras profissionais eram também influenciadas pelo jornal. A reprodução de modelos de roupas e de acessórios orienta todo o trabalho de ilustração dos impressos Lombaerts. Os anúncios da Typ. e Livraria Lombaerts \& Comp., no próprio jornal $A$ Estação, explicita o que seriam as publicações que o complementavam: o Tratado sobre o ensino do corte das vestes de ambos os sexos por 'AGDA', o Tratado de Trabalhos de agulha (A ESTAÇÃO, 31 de dezembro de 1900, s.p.) e o Tratado de costura, por Mme. Aubé (15 de junho de 1879, p. 100).

Folheando o jornal on-line na BNDigital ${ }^{10}$ e um exemplar sobrevivente do Tratado de costura (AUBÉ, 1881), podemos aferir que as ilustrações têm um caráter pedagógico, uma vez que, nelas, a figuração é extremamente clara e legível, os desenhos são, geralmente, sombreados para dar relevo aos objetos representados. 0 desenho dos pontos, da costura e dos materiais usados na confecção dos "ilhozes abertos" da figura 2 (AUBÉ, 1881, p. 42), na sua precisão gráfica, constitui por si mesmo os meios que tornam a comunicação possível (FRANCASTEL, 1993), pois "informa uma atividade fundamental" (FRANCASTEL, 1993, p. 3) que é a costura e o modo de fazê-la.

\section{FIGURA 2 - ILHOZES ABERTOS}

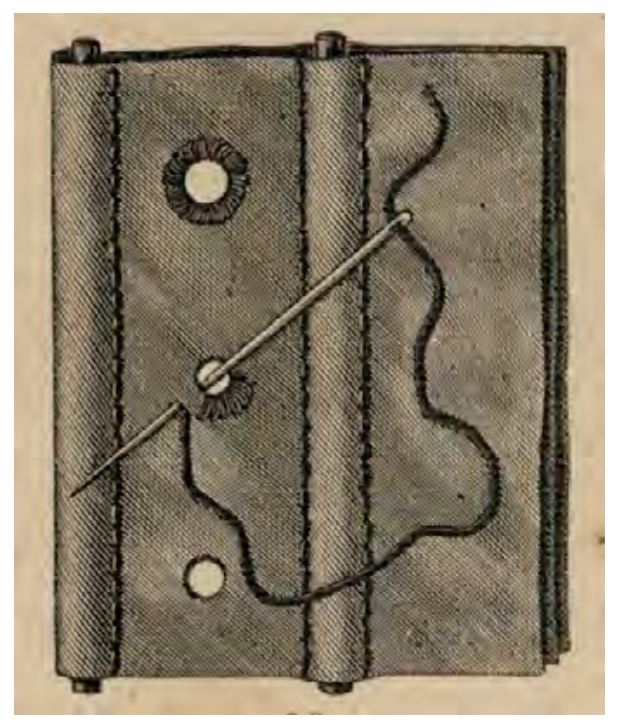

FONTE: Tratado de costura, 1881, p. 42. Acervo da autora.

\section{FIGURA 3 - COLLETE OU ESPARTILHO}

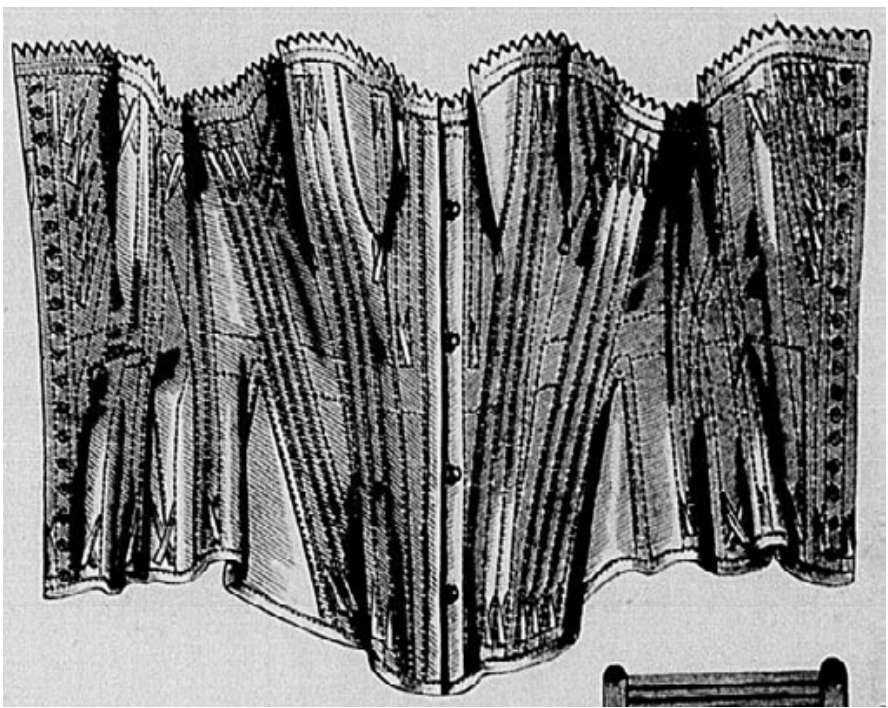

FONTE: A Estação, 15 de julho de 1882, p. 148.

BNDigital - Biblioteca Nacional Digital do Brasil.

\footnotetext{
10 manual e o jornal na versão em português eram redigidos por Antonine Aubé, a mesma redatora do La Saison, cujo exemplar de 1o de janeiro de 1883 consta XVIme Année (LA SAISON, 1ํ janvier 1883). No jornal em português, encontramos menção a dois outros manuais: Tratado completo do filet e do filet guipure e oTratado especial de macramé (A ESTAÇÃO, 15 de agosto de 1880, p. 154 e p. 133 respectivamente).
} 
A confecção dos "ilhozes abertos" (figura 2) é endereçada aos "corpinhos decotados atados por detraz" (AUBÉ, 1881, p. 42) e, por isso, reforça os elementos de estruturação dessa peça representando duas barbatanas paralelas, três folhas de tecidos sobrepostas, as costuras lineares que alinham as barbatanas, a linha, a agulha e os pontos da costura dos furos circulares. A agulha está na posição transversal da direita para a esquerda de modo a indicar a costura manual e a posição em que a agulha penetra a trama têxtil. É uma ilustração de caráter informativo (REIS, 2017).

No entanto, aqui alcançamos os limites de comunicação do figurativo e somos impulsionados a buscar um segundo elemento de comunicação do processo de confecção dos "ilhozes abertos": o texto ao qual a imagem é associada. A costura linear, que pelo aspecto pode ser manual, é idêntica à costura representada na ilustração de número 23a na seção de "costuras" do mesmo manual (AUBÉ, 1881, p. 35). Se pelo desenho não podemos aferir a natureza da costura, o texto diz que se trata de "algumas costuras das que são mais especialmente empregadas e podem ser executados por meio da machina" (AUBÉ, 1881, p. 35). Além disso, o figurativo não nos comunica as propriedades dos materiais e é o texto quem nos dirá que o reforço dos ilhoses é feito em cadarço, material visível entre as duas folhas de tecido, à esquerda. 0 texto recomenda sustentar cada "beira" do "corpinho atraz" com "duas finas barbatanas ou orla dura sustida por dois pespontos". Continua indicando recobrir os furos com fios de "linho muito forte" e caseá-los com "torçal de seda", já que os ilhoses de metal são pregados por "operarios especiais".

No entanto, se as instruções dos "ilhozes abertos" estão no manual de costura (figura 2), é no jornal que visualizamos a peça para a qual o acabamento é recomendado: o "collete", também nominado de "espartilho" (figura 3), item cujo uso atravessou a belle époque, apesar das inúmeras tentativas de ser banido do guarda-roupa feminino nesse período. Podemos compreender que o jornal e o manual de costura são complementares e as razões nós alcançamos na "correspondência" de n. 36.011, segundo a qual,

[o] Tratado de Costura, tem por fim ensinar as minuciosidades que não pode-
mos estar repetindo constantemente ao descrever as toilettes; todas as nossas
assignantes lucrariam portanto possuindo essa obrinha que demonstra com mi-
nuciosidade: $1^{\circ}$ processo de levantamento de moldes e suas alterações quer para
feitios similares, quer para dimensões de corpos diversos, $2^{\circ}$ o corte da fazenda,
$3^{\circ}$ a confecção das peças de vestuarios e seus enfeites. (A ESTAÇÃO, n. 11, 15 de
junho de 1879, p. 100)

Os impressos Lombaerts trabalham com os três vestuários categorizados por Roland Barthes (2009) em o vestuário-imagem, o vestuário-escrito e o vestuário-real. 0 vestuário-imagem alcança vários tipos de representação plástica: o figurino (figura 1), o desenho técnico (figuras 2 e 3) e os moldes (figura 4), que são fundamentais na construção das formas das complexas silhuetas divulgadas pelos jornais.

Nos anexos de moldes, podemos ver a complexidade do sistema de comunicação gráfica e sua interação com as palavras. Nele, visualizamos a roupa no corpo enquanto objeto tridimensional; as partes dos moldes em miniatura e em tamanho real; e os bordados, em vários tipos, que compõem a proposta de figurino. Os moldes trazem uma carga densa de informações expressas em códigos próprios: linhas retas, pontilhadas, curvas, tracejadas 
etc., cada uma com um sentido próprio e que implicava saber lê-las ainda que a legenda estivesse sempre ao lado. Os moldes em diversas formas, linhas e tamanhos eram sobrepostos de modo que a costureira deveria ser atenta e conhecer sua semântica. 0 vestuário-real, terceira categoria de Barthes (2009), é aquele que, concebido em algum ateliê parisiense, foi desenhado e impresso no jornal e que inspirava um outro, aquele que poderia ser construído em algum ateliê ou em uma residência de costureira em algum outro lugar.

Em Villa Platina, o objeto têxtil, que testemunha a difusão da moda da belle époque, além das inúmeras fotografias de casais (OLIVEIRA, 2016), é uma blusa que fez parte do vestido de casamento de Inhazinha, Maria Umbelina de Amaral (NOVAES, 2018). Essa peça, também chamada de spencer, foi usada em 12 de outubro de 1912 e se caracteriza por uma blusa dupla de cor marfim que apresenta corpinho em forma de "V" com manga longa inteiriça (quimono ou "dolman") e gola alta junto ao queixo. Ela apresenta o característico "peito de pombo" e o corte inteiriço dispõe o corte do tecido em "fio reto" na parte da frente e em "corte viés" nas costas. É uma blusa dupla, manufaturada em formas fluidas em crepe de seda e tules bordados na peça superior e em morim na peça do forro espartilhado.

\section{FIGURA 4 - PAPEL DE MOLDES}

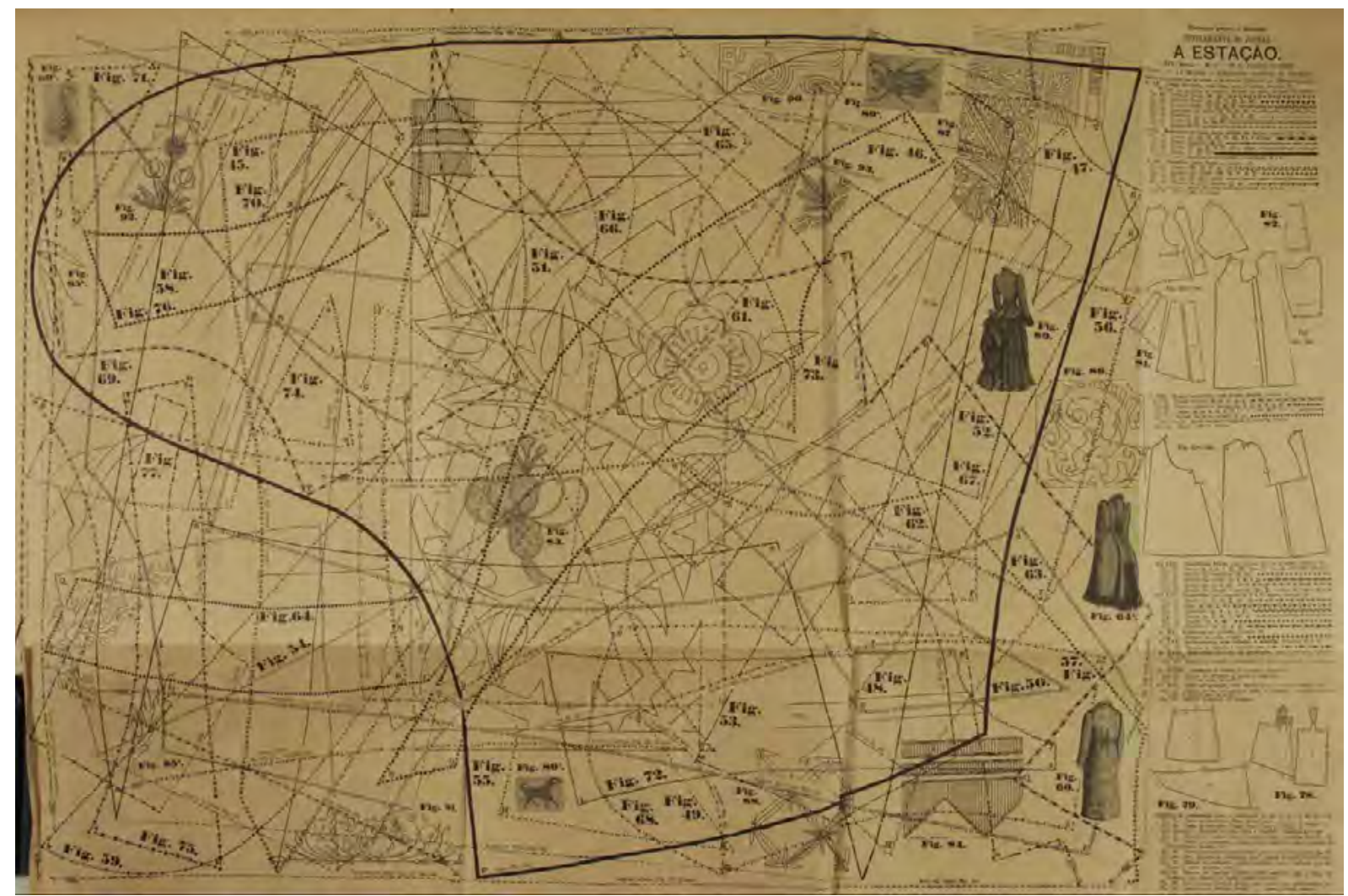

FONTE: A Estação, 15 de janeiro de 1885, s.p. BNDigital - Biblioteca Nacional Digital do Brasil.

A concepção de um modelo nos ateliês de Paris e suas reconstruções em vestuário-imagem ou em vestuário-real implicam em processos permeados de interpretações e 
adaptações no que tange a materiais e técnicas, como certamente ocorreu com o spencer de Inhazinha.

\section{0 entrelaçamento do Estado e dos jornais de moda no ensino de "corte e costura" na belle époque brasileira}

A imprensa, "revolução Gutenberguiana" (BALDINI, 1995, p. 9) do século XVI, que foi inaugurada e difundida no Ocidente com a impressão da bíblia (BALDINI, 1995; GRUZISNKI, 2014), será o mais eficiente meio de comunicação do século XIX, e a moda um tema que perpassa suas diversas categorias: os jornais de política e economia, as revistas de humor e os jornais femininos, entre outros. A cultura visual será uma linguagem que permitirá a comunicação dos conteúdos de moda para além do texto escrito, favorecendo a rede de circulação de ideias e de cultura material, europeias e norte-americanas, estruturadas em uma organização político-econômica transnacional (GRUZINSKI, 2014). Nas dimensões nacional (Brasil), regional (Minas Gerais) e local (Villa Platina/Ituiutaba) às quais nos referimos, essa rede se estabelecia no entrelaçamento que envolveu o Estado, a educação confessional, a educação laica, a educação profissional e os impressos da editora Lombaerts no Brasil, assim como em muitos países europeus.

Os tratados de corte e costura eram, em geral, publicações vinculadas às revistas de moda. Na Itália, o manual de Rachele Senta, La sarta $(1911)^{11}$, por exemplo, era ligada à $L a$ Moda Illustrata (1912). O Manual de La Moda Elegante (1878) era uma publicação ligada à revista espanhola La Moda Elegante (22 de março de 1884) e o Tratado de costura, publicado no Brasil, era vinculado ao jornal de moda A Estação (1879-1904).

Das revistas de moda, os manuais técnicos se entrelaçavam aos programas de educação, uma vez que alguns deles eram adotados por programas escolares, tais como o manual Confezione d'abiti per signora e l'arte del taglio, de Emilia Cova (1895), foi adotado pela Scuola professionale pareggiata Regina Margherita Bologna, na Itália; o manual de Mme. Alice Guerre (1888), que foi adotado pela escola normal Institutrices de la Seine, em Paris, França; o manual de Mme. Antonine Aubé, traduzido do francês, que foi adotado pela Escola Normal da Côrte no Rio de Janeiro, em 1883. De 1898 a 1904, o Tratado sobre o ensino de corte das vestes de ambos os sexos por 'AGDA', que foi traduzido do francês e publicado no Brasil pela Lombaerts, sendo adotado como manual pelo Conselho Superior de Instrucção Publica Municipal do Districto Federal para as escolas elementares do sexo feminino. Vale a pena ressaltar que o tratado de costura foi adotado ainda no fim do II Império, pela Escola Normal da Côrte. Após a instauração da República, o Conselho Superior de Instrução Pública Municipal do Rio de Janeiro recomendaria o Tratado sobre o ensino de corte das vestes de ambos os sexos por 'AGDA' para as escolas primárias. Com a mudança de regime, os impressos Lombaerts permaneceriam ligados aos programas escolares.

\footnotetext{
${ }^{11}$ Ao longo do ano de 1912, a revista La Moda Illustrata publicou anúncios do manual "útil a toda mulher que se prepara para cortar e arrumar suas próprias roupas; é rico em ilustrações e impresso em papel de luxo" (La Moda Illustrata, 4 gennaio 1912, p. 15).
} 
Moda e cultura visual, adotadas na difusão de seus conteúdos, foram amplamente usadas pelas forças econômicas e políticas favorecendo a mundialização (GRUZINSKI, 2014) de ideias e de cultura material relativas a comportamentos, a gostos, a modas, a figurinos. Essa circulação permitiu a difusão da cultura e das técnicas de construção de roupas (corte, costura e bordados) no Brasil, chegando, por meio de várias escalas e passagens, a conectar Paris a Villa Platina. Pelas revistas femininas e manuais técnicos, os sistemas da moda e de mensuração favoreciam a expansão econômica francesa no Brasil e a mulher seria um elemento fundamental nessa difusão.

\section{Referências}

Jornais

A ESTAÇÃo: jornal illustrado para a familia (1879-1904). BNDigital - Biblioteca Nacional Digital do Brasil. Disponível em: http://memoria.bn.br/DocReader/DocReader. aspx?bib=709816\&PagFis=1\&Pesq=. Acesso em: 13 jul. 2018.

ALMANACH UBERABENSE. Uberaba: Livraria Livraria Secolo XX, 1903. Arquivo Público de Uberaba.

ALMANAK LAEMMERT: almanaque administrativo, mercantil e industrial do Rio de Janeiro, 1859. BNDigital - Biblioteca Nacional Digital do Brasil.

LA MODA ELEGANTE: jornal de las familias (1860-1927). Biblioteca Virtual de Prensa Histórica - Gobierno di España. Disponível em: http://prensahistorica.mcu.es/es/consulta/ registro.cmd?id=1029207. Acesso em: 20 jan. 2019.

LA SAISON: journal illustre des dames. Trecadis.diba.cat - Barcelona: 1883-1908. Disponível em: https://trencadis.diba.cat/Trencadis/imgview/trencadis/diba13809?contentFlg=0\&hl_ text=la\%20saison. Acesso em: 13 jul. 2018.

MONITOR UBERABENSE. Uberaba: 17 de outubro de 1885, Anno V, n. 257. BNDigital Biblioteca Nacional do Brasil. Disponível em: http://memoria.bn.br/DocReader/DocReader. aspx?bib=709816\&PagFis=1\&Pesq=. Acesso em: 10 jul. 2018.

\section{Documentos raros/métodos de costura}

AUBÉ, Antonine. Tratado de costura: publicação do jornal A Estação. Rio de Janeiro: Typ. e Livraria Lombaerts \& Comp., 1881. Arquivo: Maristela Novaes.

COVA, Emilia. Confezione d'abiti per signora e l'arte del taglio. Milano: Ulrico Hoepli, 1895. Arquivo: Biblioteca dell'Archiginnasio, Bologna, província da Emimiglia- Romagna, Itália. 
GUERRE, Alice. Nouvelle méthode de coupe et manière de faire ses robes soi-même. Paris: Librairie de Firmin-Didot et Cie., 1888 (Quinquième Édition). Arquivo: Biblioteca Maruceliana di Firenze, Florença, província da Toscana, Itália.

MANUAL DE LA MODA ELEGANTE. Madrid: MDCCCLXXVIII (1878), Espanha: Editorial Maxtor, 2005 (Edicion Facsimil del 1878). Arquivo: Maristela Novaes.

SENTA, Rachele. La sarta: Manuale pel taglio e confezione degli abiti e biancheria. Col. Manualetti Pratici, n. 6. Milano: Società Editrice Sonzogno, 1911. Arquivo: Biblioteca Multimediale Arturo Loria, Carpi, província de Modena, Itália.

\section{Documentos originais}

CNSD. Álbum formandas 1908-1940: Colégio Nossa Senhora das Dores. Uberaba: Arquivo CNSD [s.d.], Livro I e II (CD-ROM).

ESCOLA NORMAL DA CÔRTE. Programma de costuras. Rio de Janeiro: Typ. Nacional, 1883. Arquivo Nacional do Rio de Janeiro.

OLIVEIRA, Rodolfo. Fotografias de casais: Coleção Dr. Rodolfo Oliveira. Ituiutaba: Casa da Cultura de Ituiutaba, 2016.

MARTINS FILHO, Villela. Livro Contábil da empresa Villela Martins \& Cia - 1913, v. 1 e v. 2. Ituiutaba: Centro de Pesquisa, Documentação e Memória do Pontal (CEPDOMP) da Faculdade de Ciências Integradas do Pontal (FACIP) da Universidade Federal de Uberlândia (UFU) ^ - CEPDOMP, 2015 (2 CD-ROM).

\section{Leis}

BRASIL. Decreto Lei n. 981 de $1^{0}$ de dezembro de 1890: Reforma Benjamin Constant. Disponível em: http://www2.camara.leg.br/legin/fed/decret/1824-1899/decreto-981-8novembro-1890-515376-publicacaooriginal-1-pe.html. Acesso em: 19 maio 2016.

MINAS GERAIS. Decreto 1947 de 30 de setembro de 1906 - Programma do Ensino Público Primário no Estado de Minas Gerais - Reforma Afonso Pena. Belo Horizonte: Imprensa Oficial de Minas Gerias, 1907. Disponível em: http://www.lexml.gov.br/urn/ urn:lex:br;minas.gerais:estadual:decreto:1906-09-30;1947. Acesso em: 7 maio 2016.

MINAS GERAIS. Lei estadual n. 439 de 28 de setembro de 1906 - Autoriza o Governo a Reformar o Ensino Primário, Normal e Superior do Estado e dá Outras Providências. Coleção das Leis e Decretos de Minas Gerais - 28/9/1906. Col.1. Disponível em:https://www.almg.gov.br/ consulte/legislacao/completa/completa.html?tipo=LEI\&num=439\&ano=1906\&aba=js_ textoOriginal. Acesso em: 22 nov. 2012. 
BALDINI, Massimo. Storia della comunicazione. Enciclopedia Tascabile. Roma: Newton Compton Editori, 1995.

BARTHES, Roland. Sistema da moda. São Paulo: Martins Fontes, 2009.

BICHUETTE, Monica M. Teixeira Vale; LOPES, Maria Antonieta Borges. Dominicanas: cem anos de missão no Brasil. Uberaba: Prefeitura de Uberaba - Fundação Cultural de Uberaba/ Editora Vitoria, 1986.

BRAUDEL, Fernand. Civiltà materiale, economia e capitalismo: le strutture del quotidiano (secoli XV-XVIII). Torino: Einaudi, 2006.

CALKINS, Norman Allison. Primary object lessons for training the senses and developing the faculties of children: a manual of elementary instruction for parents and teachers. New York: Harper \& Brothers Publishers, 1870. Disponível em: https://archive.org/stream/ primaryobjectles00calk3\#page/94/mode/2up. Acesso em: 22 maio 2016.

COSTA, Carlos. A revista no Brasil do século XIX: a história da formação das publicações, do leitor e da identidade do brasileiro. São Paulo: Alameda, 2012.

DUARTE, Constância Lima. Imprensa feminina e feminista no Brasil: século XIX dicionário ilustrado. Belo Horizonte: Autêntica, 2017.

EMERY, Joy Spanabel. A history of the paper pattern industry: the home dressmaking fashion revolution. London/New York: Bloomsbury, 2014.

FRANCASTEL, Pierre. A realidade figurativa. 2. ed. São Paulo: Editora Perspectiva, 1993.

FRANCHINI, Silvia. Editori, lettrici e stampa di moda: giornali di moda e di famiglia a Milano dal “Corriere delle Dame” agli editori dell'Italia unita. Milano: Franco Angeli, 2002.

GRUZINSKI, Serge. As quatro partes do mundo: história de uma mundialização. Belo Horizonte/São Paulo: Editora UFMG/EDUSP, 2014.

MALERONKA, Wanda. Fazer roupa virou moda: um figurino de ocupação da mulher (São Paulo 1920-1950). São Paulo: Editora Senac, 2007.

MENDES, Valerie D.; HAYE, Amy de la. The house of worth: portrait of an archive. London: V\&A Publishing, 2014.

MILANEZ, José Frazão. Histórico do sistema métrico decimal. Rio de Janeiro: Jornal do Commercio, 1942. 
MOURÃO, Paulo Krüger Corrêa. 0 ensino em Minas Gerais no tempo da República. Belo Horizonte: Ed. do Centro de Pesquisas Educacionais de Minas Gerais, 1962.

ROCHE, Daniel. A cultura das aparências: uma história da indumentária (séculos XVII-XVIII). São Paulo: Editora Senac, 2007.

SELTIMI, Bruno. Enciclopedia "la moda maschile": ad uso del tagliatore sarto da uomo. 8. ed. Milano: Ed. La Moda Maschile, 1942.

SODRÉ, Nelson Werneck. História da imprensa no Brasil. 2. ed. Rio de Janeiro: Edições do Graal, 1977.

\section{Dissertações e artigos em jornais e anais de congressos online}

BASTOS, Maria Helena Camara. Ferdinand Buisson no Brasil: pistas, vestígios e sinais de suas idéias pedagógicas (1870-1900). Revista História da Educação / History Education Journal, v. 4, n. 8, p. 79-109, 2000. Disponível em: http://seer.ufrgs.br/index.php/asphe/ article/view/30140/pdf. Acesso em: 15 abr. 2016.

D’ESQUIVEL, Márcio Oliveira; SANT'ANA, Claudinei de Camargo. Revista do Ensino Primário e o Ensino de Matematica pelo Método Intuitivo na Bahia (1892-1893). Anais... XII Seminário Temático Saberes Elementares Matemáticos do Ensino Primário (1890-1970): o que dizem as revistas pedagógicas? (1890-1970), Auditório Tristão de Athayde, Escola de Educação e Humanidades - PUCPR. Data: 8, 910 e 11 de abril de 2015. Disponível em: http://www2.td.utfpr.edu.br/seminario_tematico/ANAIS/31_DESVEQUIEL_SANTANA.pdf. Acesso em: 10 jul. 2018.

HERNÁNDEZ, Fernando. Elementos para uma génesis de um campo de estúdio de las prácticas culturales de la mirada y la representación. Visualidades: Revista do Programa de Pós-Graduação em Arte e Cultura Visual, Faculdade de Artes Visuais - Universidade Federal de Goiás, Goiânia, v. 4, n. 1 e 2, p. 13-62, 2006. Disponível em: https://www.revistas.ufg.br/ VISUAL/article/view/17998. Acesso em: 8 jun. 2018.

NOVAES, Maristela. Analisando roupas, redescobrindo histórias: práticas a partir do estudo de um spencer de espólio familiar. Anais. IV Encontro Centro-Oeste de Design de Moda, Faculdade de Artes Visuais - Universidade Federal de Goiás (UFG), Goiânia, p. 1-10, 2010. (CD-ROM) - ECOM.

NOVAES, Maristela. Caminho das pedras: uma ressignificação do olhar e da experiência no processo de construção de roupas. 2011. 200 f. Dissertação (Mestrado) - Programa de PósGraduação em Cultura Visual - Faculdade de Artes Visuais, Universidade Federal de Goiás (UFG), Goiânia, 2011. Disponível em: https://files.cercomp.ufg.br/weby/up/459/o/2011_ Maristela_Abadia_Fernandes_Novaes.pdf. Acesso em: 10 out. 2017. 
NOVAES, Maristela. Storia della costruzione di un oggetto della moda fra otto e novecento uno spencer liberty ai confini di Minas Gerais: aspetti culturali e materiali. 2018. 334 f. Tese (Doutorado) - Programa de Pós-Graduação "Storia Culture Civiltà", Università di Bologna, UniBO, Bolonha, Itália, 2018. Disponível em: http://amsdottorato.unibo.it/. Acesso em: 21 nov. 2018.

REIS, Ana Paola dos. Sentidos desenhados no intangível: um olhar sobre ilustração de moda e visualidades. 2013. 103 f. Dissertação (Mestrado) - Programa de Pós-Graduação em Cultura Visual - Faculdade de Artes Visuais, Universidade Federal de Goiás (UFG), Goiânia, 2013. Disponível em: https://culturavisual.fav.ufg.br/up/459/o/2013_Ana_Paola_dos_Reis.pdf. Acesso em: 15 jun. 2018.

\section{Agradecimentos}

Agradeço muito à Profa. Rosane Rocha Pessoa (FL-UFG) pela leitura crítica e cuidadosa do texto e por sugestões preciosas para a escrita deste artigo. 